\title{
Высокоскоростная многоканальная линия связи с переменной компенсацией дисперсии: подавление нелинейных искажений
}

\author{
Е.Г. Шапиро, Д.А. Шапиро* \\ Институт автоматики и электрометрии СО РАН, \\ Новосибирский государственньй университет \\ *E-mail: shapiro@iae.nsk.su
}

DOI: 10.31868/RFL2020.128-129

Для увеличения пропускной способности линий волоконной связи используется многоканальная передача информации, высокая скорость передачи в отдельном канале, форматы кодирования высокого порядка и др. Основными факторами искажения сигнала являются шумы усиления и нелинейные эффекты, сопровождающие распространение сигнала по линии связи.

В данной работе рассмотрена комбинация способов подавления нелинейных искажений в линии связи с нулевой средней дисперсией: большое чирпирование входных импульсов и переменная компенсация дисперсии. Показано, что одновременное использование этих способов существенно улучшает качество сигнала при многоканальной передаче информации.

Мы выполнили численный расчет распространения сигнала в рамках нелинейных связанных уравнений Шредингера [1] для трех каналов. Линия связи состояла из 10 участков вида

$$
\operatorname{SMF}(100 \text { км })+\operatorname{EDFA}+D C(i) \text {. }
$$

Здесь SMF - стандартное одномодовое волокно, EDFA - эрбиевые усилители, которые полностью компенсировали затухание сигнала на участке волокна, $D C(i)$ - $i$-ый компенсатор. Мы полагали, что компенсаторы изготовлены на основе брэговской решетки с малым затуханием. Поляризационная дисперсия не учитывалась. Обозначим $d_{i}$ величину хроматической дисперсии, которую компенсирует устройство $D C(i)$. Величины $d_{i}$ образуют арифметическую прогрессию с шагом $\Delta d$. Сумма $d_{i}$ равна $-17000 \mathrm{ps} / \mathrm{nm}$, т.е. полностью компенсирует накопленную дисперсию 10 участков SMF. Таким образом, в отличие от работы [2], для данного дизайна не требуется посткомпенсация накопленной хроматической дисперсии. Форматом модуляции был выбран 8QAM. Здесь использовались два значения амплитуды $\left(0.043 \mathrm{BT}^{1 / 2}\right.$ и $0.086 \mathrm{BT}^{1 / 2}$ ) и четыре значения фазы для каждой амплитуды. Информация кодировалась гауссовыми импульсами вида $a_{n}(\tau)=B_{n} \exp \left[-\left(\tau^{2}-i C \tau^{2}\right) / 2 T_{0}^{2}\right]$, где $B_{n}$ - амплитуда бита с номером $n, \mathrm{C}$ - параметр чирпа, $T_{0}$ задает ширину импульса, здесь $T_{0}=6$ ps. Длина битового интервала была равна 25 ps. Каналы разнесены на $100 \mathrm{GHz}$.

Ниже приведены сигнальные диаграммы для центрального канала на приемнике после обработки, разделяющей каналы и уменьшающей шумы усилителей. На рис. 1 приведен график для $\Delta d=0$ и нулевого начального чирпа. На рис. 2 изображен график для $\Delta d=288.89 \mathrm{ps} / \mathrm{nm}$ нулевого чирпа $C=0$. На pис. 3 показан график для $\Delta d=222.22 \mathrm{ps} / \mathrm{nm}$ и $C=5$. 

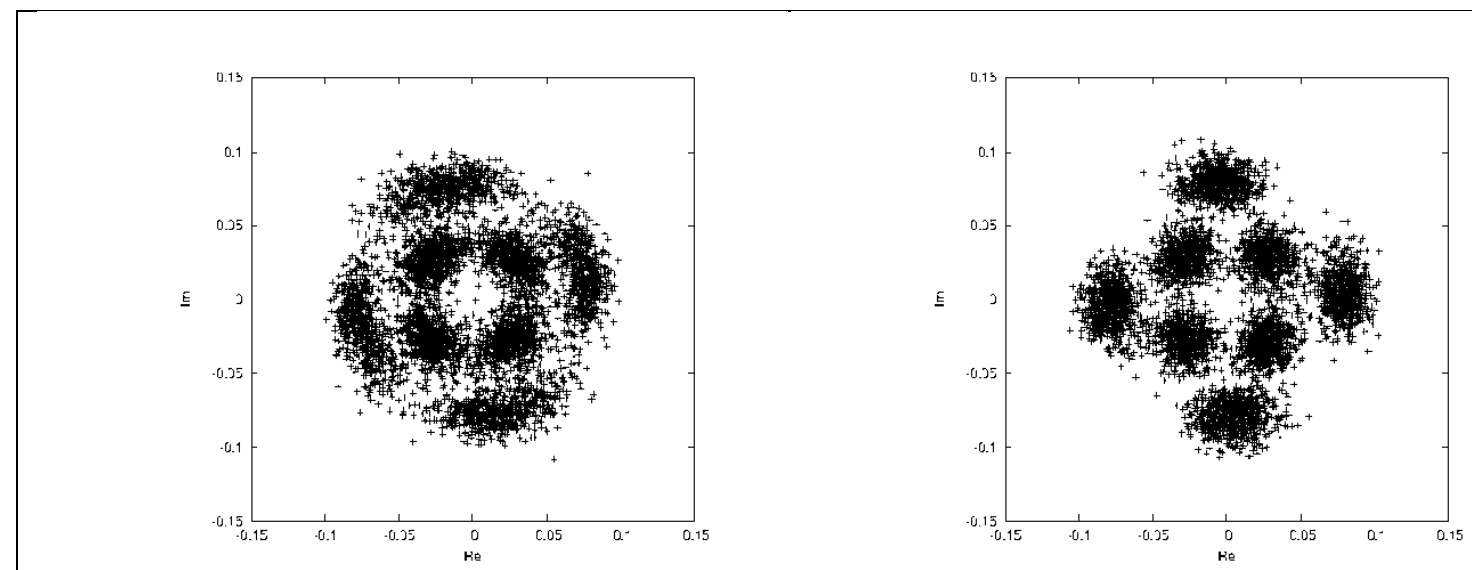

Рис. 1.

Рис. 2.

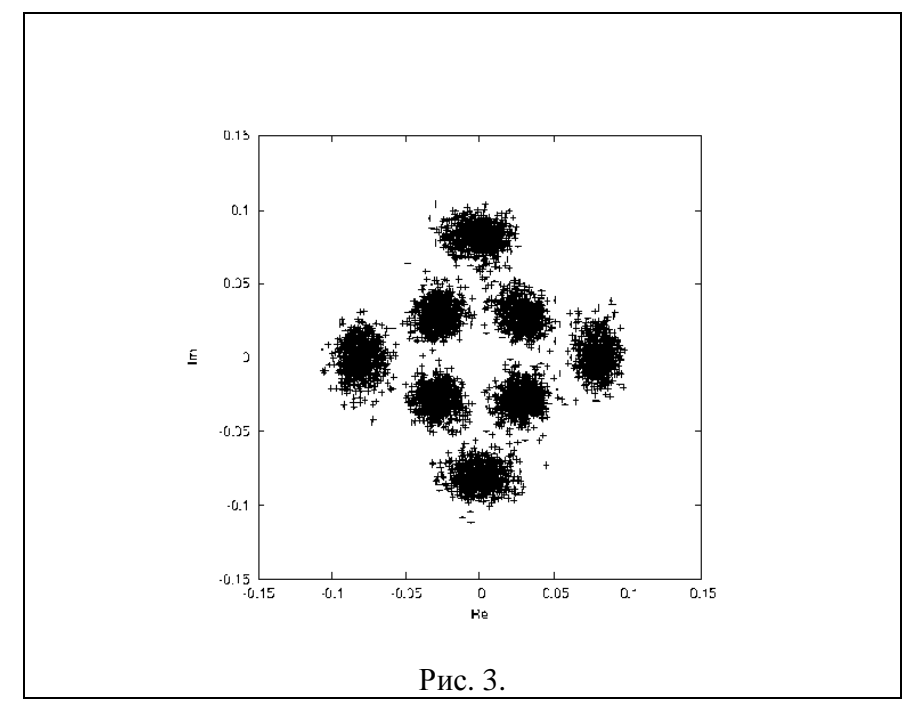

При большом значении чирпа каналы перекрываются в частотной области. Однако амплитуды частот сильно чирпированного импульса малы, поэтому искажения от межканального взаимодействия носят линейный характер и могут быть существенно уменьшены при обработке. Видно, что предложенные механизмы подавления нелинейных шумов эффективно подавляют внутриканальные нелинейные искажения

Работа выполнена при поддержке Министерства науки и высшего образования РФ, гос. рег. № AAAAA17-117062110026-3.

\section{Литература}

[1] G. P. Agrawal, Nonlinear fiber optics, Amsterdam, Elsevier, 2007

[2] Е. Г. Шапиро, Д. А. Шапиро, Кв. электрон., 50(2) 184-186 (2020). 